\title{
Academic Development of Young Teachers in Chinese Universities: A Social Capital Perspective
}

\author{
Liu Hong ${ }^{1} \&$ Zheng Jian ${ }^{2}$ \\ ${ }^{1}$ College of International Studies, Southwest University, Chongqing, China \\ ${ }^{2}$ Basic Teaching Department, Jining Technician College, Shandong, China \\ Correspondence: Liu Hong, College of International Studies, Southwest University, 400715, Chongqing, China. \\ E-mail: lovelykitten@163.com
}

$\begin{array}{lcc}\text { Received: August 24, } 2014 & \text { Accepted: September 9, } 2014 & \text { Online Published: October 30, } 2014 \\ \text { doi:10.5539/ass.v10n21p197 } & \text { URL: http://dx.doi.org/10.5539/ass.v10n21p197 }\end{array}$

\begin{abstract}
Young teachers in colleges and universities are the main force of the teachers in colleges and universities in China, and are the core element to ensure Chinese higher education to grow vigorously. Their academic development is directly related to the level of discipline construction, the quality of college students cultivation, and the implementation of the strategy of developing country through science and education in China. This paper is to examine their academic development from a perspective of social capital multidimensionally, explore the main effect of social capital on academic development of young teachers in colleges and universities, and put forward specific countermeasures for accumulating their social capital so as to promote their academic development. First of all, to raise their subjectivity and accumulate their social capital can be realized through learning, training, engaging in advanced studies, enhancing one's personality charm, widely participating in social practice activities, and so on. Second, to accumulate external social capital is the duty-bound responsibility of Chinese government and Chinese administrative department of education, that is, to create a system environment and to optimize the financial environment for the development of young teachers in colleges and universities, to establish and improve the talent flow mechanism, to create a harmonious, relaxed and positive academic environment, and to establish and improve the fair and equitable evaluation system.
\end{abstract}

Keywords: social capital, universities, young teachers, academic development

\section{Introduction}

In an era of the pursuit of academic innovation, scientific research is a core strategy to develop academic excellence for colleges and universities. The role of scientific research to colleges and universities has been made insightful analysis by some experts. Cao Aihua (2007: 24) mentioned that "academic development is the guarantee of a good university, especially a high-level university; high-caliber scientific research helps to create a group of high-caliber teachers, construct high-level discipline, provide students with high-level education, and improve the university's academic prestige and its status in society at the same time". Therefore, besides undertaking the task of teaching and cultivating people, teachers in colleges and universities shoulder an important scientific research mission, that is, to improve the teaching quality, the discipline construction and the prestige of the university through their own academic development. Young teachers in colleges and universities are the future relying force of scientific research in higher educational institutions. They should make contributions to the realization of the idea of the academic excellence of a university and the discipline construction of colleges and universities. However, in reality a large number of young teachers present a weak scientific research situation, which seems to make them difficult to complete this mission. How to improve the academic development of young teachers in colleges and universities, so as to change their weak scientific research situation has become a hot topic among many scholars. Papers such as "Problems and Countermeasures of Cultivating the Scientific Research Ability of Young Teachers in Colleges and Universities" (Zhang, 2012), "Discussion on the Cultivation of the Scientific Research Ability of Young Teachers in Colleges and Universities" (He, 2009), and "On the Cultivation of the Scientific Research Ability of Young Teachers in Colleges and Universities" (Geng, 2012) mainly start from the experience cognition of the real-life scientific research situation of young teachers in colleges and universities, analyze the existing problems, and put forward some countermeasures in the end. The conclusions of these studies are based on the experience cognition and 
subjective inference of the researchers. Therefore, phenomenon description and experience summary account for a large proportion in most of the papers, and there are somewhat deficiencies in academic basis and theoretical deduction.

In order to enhance the depth of the theoretical research of this field, the present study examines the academic development of young teachers in colleges and universities on the basis of social capital theory. Social capital is one of the social theories gradually developed and improved in the past thirty years, with strong explanatory power and adaptability, which has aroused the attention and recognition from all walks of life. Foreign scholars have studied the role of social capital on school development. Hargreaves (2001), for example, found that if a school had adequate social capital, high levels of trust would appear in its network relationship. Such trust will have a strong network and cooperative relations among the members, and will make it easier for each member to solve all sorts of problems. Firestone \& Martinez (2007) examined the relationship between urban school leadership rules and social capital. According to them, social capital can provide resources and services for the development of the school. This social capital can be divided into two kinds, namely, on-campus social capital and off-campus social capital. The role of on-campus social capital is the development of teachers' professional skills and the improvement of teaching effect, while the role of off-campus social capital is mainly the introduction of resources and experts needed by the school development. Dee, Ha \& Jacob (2007) studied why the small-size school in the United States is more effective in improving the students' studies. Their conclusion is that the small-size school can improve the school's social capital effectively, that is, the small-size school is more effective at work in the mobilization of parent volunteers to participate in school education. In general, the researchers focused on the examination of the influence of social capital on school education from the aspect of the school and students. And there is a lack of research from the aspect of teachers. Therefore, it is of strong academic innovation significance to examine the academic development of young teachers in colleges and universities under the perspective of social capital. A concern of social capital theory is "resources embedded in the social structure" (Nan, 2005, p. 28). Given Chinese traditional culture attach great importance to individuals' social structure and the corresponding human relationships, which might bring an individual different resources and help him or her to carry out activities smoothly and accomplish his or her aims, it is possible and necessary to examine the current existence pattern of young teachers in Chinese universities and the influencing factors encountered in the process of development. Based on the social capital theory, this paper makes a special effort to analyze how the young teachers in colleges and universities should accumulate social capital in order to promote their academic development.

\section{Methodology}

First, the researcher used the method of literature analysis: collected previous studies on social capital and academic development of young teachers in colleges and universities, read carefully, and summed up main findings of these studies which were used as the basis of this article, and tried to find the limitations of previous studies which were used as the innovation of this article. The literature analysis showed that theoretical aspects of the field of academic development of young teachers in colleges and universities need to be strengthened, and studies applying social capital theory to examine academic development of young teachers in colleges and universities are relatively rare. Therefore, to examine academic development of young teachers in colleges and universities under the social capital theory is topic of theoretical value and practical significance. Second, the researcher used the method of logical reasoning: on the basis of reviewing difficulties of academic development of young teachers in colleges and universities, the researcher used social capital theory as a guidance to analyze how young teachers in colleges and universities accumulate social capital to promote their academic development.

\section{The Research Finding}

\subsection{Difficulties of Academic Development of Young Teachers in Colleges and Universities}

With the rapid development of higher education in China, the teacher resources in Chinese universities are becoming stronger and stronger. In recent years, age composition of teachers in Chinese universities has undergone great changes, for a large number of young teachers have joined in the teaching staff of Chinese universities, and the age composition of teachers in universities has a younger trend. "According to the statistics of the Ministry of Education, the proportion of teachers aged under 40 in Chinese universities and colleges has exceeded more than two-thirds" (Wang, 2012). Young teachers have become an important part of university teacher forces and universities' major power for teaching, research and service to the society in China.

According to the recent Survey Report of Chinese Young Teachers in Colleges and Universities (Wang, 2012), young teachers in colleges and universities are high pressure groups, among whom, nearly ninety percent feel 
stressed, 72.3 percent are very stressed, 36.3 percent are highly stressed. Moreover, more than eighty percent of them think themselves to be at the middle or lowest level of the society. These respondents said that the sources of their pressure mainly came from three aspects - heavy scientific research tasks, extensive tutorial missions, and little economic income.

Scientific research is the affair that young teachers in colleges and universities must face. Many colleges and universities directly link the promotion of job title and position with quantitative indicators, such as the number of published papers, the number of published books, and the number of applied projects. Besides, whether a teacher can get a high-level job title such as professor is closely related to his or her salaries, status and development opportunities. Therefore, Liu Guoquan (2010) pointed out that teachers' scientific research is the decisive factor of his or her academic status, economic status, and political status. Due to the fact that most of the young teachers' scientific research quality, such as knowledge structure and research methods cannot achieve a high level, they feel it hard to do research theoretically and empirically. If these young teachers lack guidance of academic development in the personal relationship network and organizational network, their scientific research consciousness might become weak because of frustration and helplessness, which to a certain extent, will affect the output of their scientific research achievements.

In addition, the biggest problem that young teachers in colleges and universities face is perhaps a series of struggle and hardship caused by economic distress, which make it difficult for them settle down to do academic research. Most of the young teachers are in the early stages of their career and life, have relatively low job titles and positions, and meagre wage income, but they have to bear heavy economic burden, such as getting married, buying a house, children education, supporting the elderly, association, and financial cost of further studies. Social sciences academic press published a book recently, named Report for Social Development of Beijing, in which, a survey of young teachers' income in universities is becoming a hot topic of Chinese media reports. The emphasis of the reports was young teachers' embarrassment in economic life, such as the wage income of young teachers who just participate in this work is generally low, and the number of the moonlight clan is still too many (Huang, 2013). The biggest challenge facing young teachers is the housing problem. Due to the long-term high housing prices in China and the young teachers' own reasons, such as long time of education, little savings, low income, and in the period of marriage and childbirth, they live in a conflict and contradiction between their strong demand for housing and inability to afford it. These conflicts and contradictions make the young teachers in colleges and universities give more classes so as to earn more tuition fees or take other part-time jobs to solve the economic problems. The result is these young teachers spend little time on scientific research and find it difficult to calm down to do research. But the fact is that fine scientific research comes from slow work. Only the researcher is willing to cool his heels and sit on the bench, can high-quality research result be produced.

At present, it is unrealistic to demand China to draw out policies and measures to encourage, help and promote the development of young teachers growth development, establish and perfect social security system of overnight, so as to fundamentally change their current situation of economic distress. But there are other feasible ways to help the academic development of young teachers in colleges and universities. Social capital is a good way. Young teachers in colleges and universities can achieve their purpose in scientific research through investing and using social resources embedded in personal relationship network or organizational relationship network such as work unit. Therefore, the accumulation of young teachers' social capital to eliminate the confusion and pressure that they must face in scientific research is an important prerequisite to fully arouse their working enthusiasm, perfect and develop their social values.

\subsection{Ways to Accumulate Social Capital and Promote Academic Development}

\subsubsection{The Accumulation of One's Social Capital}

Social capital is a highly inclusive concept. From the broad sense, the present study defines it as social resources embedded in the social relationship network, as well as advantageous factors that can help to improve the carrying out of one's social practices smoothly. The social capital of young teachers in colleges and universities refers to their own advantages, special strengths, and all factors that can promote their teaching activities and scientific research smoothly.

In particular, the social capital of young teachers in colleges and universities mainly include their professional quality, comprehensive ability, and individual existence condition, all of which are their huge social wealth and basic conditions for helping to practise their professional ideals and realize their value of life.

The professional quality of young teachers in colleges and universities is a huge social capital. Generally speaking, their professional quality mainly includes ideological and political qualities, professional and moral 
qualities, scientific and cultural qualities, professional skill quality, and physical and psychological qualities, which form the modern comprehensive qualities.

The comprehensive ability of young teachers in colleges and universities is an important component of their social capital. According to Marx, subjective ability is formed in social practices, latent within the main body, manifested as objective dynamic power in the objective relationship between subject and object, and the unity of the cognitive ability and practice ability $(\mathrm{Ou}, 1985)$. Such practice ability is the guarantee factor to ensure that young teachers in colleges and universities can carry out their teaching activities smoothly. The comprehensive ability of young teachers in colleges and universities is a collection of abilities, which contains many specific abilities. In general, they include innovation ability, research ability, communication ability, operation ability, teaching skills, the ability of adaptation, error correction, adjustment and transformation.

The existing condition of young teachers in colleges and universities is also a huge social capital, which mainly manifested itself as their own characteristics, such as their way of existence, living habit, personal interests, hobbies, external features, shape, size, hair style, voice, social status, life role, family composition, marital status, gender, constellation and blood type. Different existing condition of young teachers in colleges and universities determines that there are also big differences among their attraction, influence and acting force.

To raise one's subjectivity and to accumulate one's social capital are indispensable parts in the growth and development process of young teachers in colleges and universities. And there are many ways for them to choose in the process of achieving this goal.

Learning, training and further education are three main ways for young teachers in colleges and universities to accumulate their social capital. In today's rapidly changing era, knowledge is updating at an unprecedented frequency and breadth. Therefore, young teachers in colleges and universities should have a continuous progress, open and modest character, constantly update and optimize their knowledge structure, expand their horizons, heighten their spirituality, ensure to stand in the front of the knowledge, and constantly enhance self moral cultivation at the same time.

Wide participation in social practice is another important way for young teachers in colleges and universities to accumulate their social capital, during which process, they can meet a lot of good teachers and friends, so as to extend and maintain their own social network, and accumulate abundant human resources naturally. In addition, one of the best ways to win other people's respect and love is to develop good hobbies and interests, cultivate healthy behavior and living habits, enhance personality glamour, possess graceful manners and polished appearance, and talk kindly and naturally. The improvement of these individual subjectivity help to accumulate young teachers' social capital, and lay a solid foundation for them to win science research resources.

\subsubsection{The Accumulation of External Social Capital}

External social capital of young teachers in colleges and universities refers to all the positive factors conducive to their growth development in addition to their own social capital. It is a large comprehensive collection. Specifically, it includes factors related to the growth development of young teachers in colleges and universities, such as external social environment, social background, social fashion, social atmosphere and social development trend. The accumulation of these social capital need the participation of multiple subjects to complete at multiple dimensions.

It is the duty-bound responsibility of the Chinese government and the Chinese administrative departments of education to create a good external social environment, help young teachers in colleges and universities to accumulate external social capital, and build an institutional environment for the growth development for these young teachers. The report to the eighteenth national congress of the communist party of China clearly put forward, "We should strengthen the ranks of teachers, and enhance their work ethics and professional competence as well as their sense of honor and responsibility as teachers." The national conference on education in 2013 stressed the importance and urgency of teachers' team construction in colleges and universities, and pointed out that "improving the quality of education, the key is to improve the quality of teachers". At the same time, China is establishing, perfecting, protecting and promoting the system and policy of the development of higher education, which provides a good system support for the academic development of young teachers in colleges and universities.

To optimize the financial environment for the development of young teachers in colleges and universities. The development of higher education needs strong financial support as a basis. The central government departments and local governments at all levels should attach great importance to higher education, continue to increase 
investment in higher education, strongly support young teachers' advanced studies, training and foreign exchange transactions, and create a good financial environment for their academic development.

To establish and perfect the talent flow mechanism, to implement the strategy of "going out and bring in" to broaden the horizon of young teachers in colleges and universities, to increase their chances of learning, reference and promoting self ability, to build a platform for them to achieve and accomplish goals, and to completely break the relatively closed and inbreeding ecological environment of the traditional universities. To cultivate the social mode of love and respect one's job, and selfless dedication. To foster the social atmosphere of respecting teachers and education, and commitment to learning. To implement the strategy of relying on science and education to rejuvenate the nation is an important way to attract more excellent talents long engaging in higher education, base on their own posts, devote themselves to teaching and research, and stick to their professional ideals.

Colleges and universities have more direct, unique conveniences and advantages for young teachers to accumulate their social capital. Generally speaking, universities can implement from the following aspects: encourage young teachers to do scientific research with great concentration, strongly support their academic exchange activities, create a harmonious, relaxing and positive academic environment, establish and improve the fair and equitable evaluation system, introduce, support, and cultivate young talents, improve their learning, working and living conditions, give special support to outstanding young teachers, and create promotion channels for them, so as to build a platform for them to achieve and accomplish goals.

\section{Conclusions}

Young teachers in colleges and universities are the main force of the teachers in colleges and universities in China. They are the future and hope of Chinese higher education, and the core element to ensure Chinese higher education to grow vigorously. The stock of their social capital and their scientific research strength has a direct linkage with the implementation of the strategy of developing country through science and education in China. It is of far-reaching and practical significance to pay attention to the academic development of young teachers in colleges and universities and accumulate their social capital. One of the difficulties of young teachers' academic development is that their economic pressure is too big which lead them feel it hard to engage in scientific research, and hinder their academic development to a large extent. The other is that the knowledge structure and research methods of most young teachers have not reached a high level, resulting in their academic development does not go smoothly. From the perspective of social capital, young teachers in colleges and universities can accumulate their social capital to promote their academic development from two aspects. First, to raise their subjectivity and accumulate their social capital can be realized through learning, training, engaging in advanced studies, enhancing one's personality charm, widely participating in social practice activities, and so on. Second, to accumulate external social capital is the duty-bound responsibility of Chinese government and Chinese administrative department of education, that is, to create a system environment and to optimize the financial environment for the development of young teachers in colleges and universities, to establish and improve the talent flow mechanism, to create a harmonious, relaxed and positive academic environment, and to establish and improve the fair and equitable evaluation system.

\section{References}

Cao, A. H. (2007). A study on the premise hypothesis of the scientific research incentive system of college teachers. Higher Education Exploration, 4, 24-26. Retrieved from http://www.docin.com/p683201139.html

Dee, T. S., Ha, W., \& Jacob, B. (2007). The effects of school size on parental involvement and social capital: Evidence from the ELS 2002. In T. Loveless, \& F. Hess (Eds.), Brookings Papers on Education Policy 2006-2007 (pp. 77-97). Washington: Brookings Institution Press.

Firestone, W. A., \& Martinez, M. C. (2007). Districts, teacher leaders, and distributed leadership: Changing instructional practice. Leadership and Policy in Schools, 6(1), 3-35. Retrieved from http://www.citeulike.org/user/bujangamat/article/3154455

Geng, A. L., \& Wang, Y. S. (2012). On the cultivation of the scientific research ability of young teachers in universities. Education and Vocation, 18, 71-73. Retrieved from http://www.doc88.com/p$6641991198075 . \mathrm{html}$

Hargreaves, D. H. (2001). A capital theory of school effectiveness and improvement. British Educational Research Journal, 27(4), 487-503. Retrieved from http://www.jstor.org/discover/10.2307/1502031

He, G. Y., \& Guo, L. R. (2009). Discussion on the cultivation of the scientific research ability of young teachers 
in universities. Data of Culture and Education, 32, 176-178. Retrieved from http://202.106.125.34/qk/80738X/200932/32321443.html

Huang, X. L. (2013, April 9). Low incomes, teachers in universities have no mood to teach. River Network Information Daily. Retrieved from http://www.jxnews.com.cn/xxrb/system/2013/04/09/01236 2473.shtml

Lian, R. (2007). Professional Development of Teachers. Beijing: Higher Education Press.

Lin, N. (2005). Social Capital: A Theory of Social Structure and Action. Shanghai: Shanghai People's Publishing House.

Liu, G. Q. (2010). The Study of the Influence of University Teachers' Social Capital on Their Academic Performance (Unpublished doctoral dissertation). Peking University, Beijing, China.

Pan, H. Y. (2006). Educational Research and Professional Development of Teachers. Beijing: China Light Industry Press.

Shao, P. R. (2007). Communication. Beijing: Higher Education Press.

Wang, M. J. (2012, September 14). Investigations revealed that young teachers in colleges and universities compare themselves to "Worker Bees".China Youth Daily.

Wang, Y. (2012, December 17). How to unite and influence young teachers for the party organizations in colleges and universities. Guangming network - Guangming Daily. Retrieved from http://theory.gmw.cn/ 2012-12/17/content_6037744.html

Yan, J. R. (2006). Investment of Social Capital: A New Dimension of Political Development. Beijing: Peking University Press.

Zhang, N. G. (2008). Problems and Countermeasures of college young teachers' scientific research ability. Forum on Contemporary Education, 8, 91-93. Retrieved from http://www.doc88.com/p-27640335 2936.html

\section{Copyrights}

Copyright for this article is retained by the author(s), with first publication rights granted to the journal.

This is an open-access article distributed under the terms and conditions of the Creative Commons Attribution license (http://creativecommons.org/licenses/by/3.0/). 